\title{
Establishing a Belgian Nutrition Society (BNS): Filling the Void
}

\section{Editorial}

by

\begin{abstract}
Patrice Cani ${ }^{*}{ }^{*}$, Peter Clarys ${ }^{1}$, Antoine Clinquart ${ }^{1}$, Stefaan De Henauw ${ }^{1}$, Nathalie Delzenne ${ }^{1}$, Peter Deriemaeker ${ }^{1}$, Caroline Douny ${ }^{1}$, Isabelle Guelinckx ${ }^{1}$, Inge Huybrechts ${ }^{1}$, Lieven Huybregts ${ }^{1}$, Patrick Kolsteren ${ }^{1}$, Carl Lachat ${ }^{1}$, Isabelle Laquiere ${ }^{1}$, Yvan Larondelle ${ }^{1}$, Jef Leroy ${ }^{1}$, Guy Manghuin-Rogister ${ }^{1}$, Christophe Matthys ${ }^{1}$, Patrick Mullie ${ }^{1}$, Jean Neve ${ }^{1}$, Marie-Louise Scippo ${ }^{1}$, Isabelle Sioen ${ }^{1}$, Anne-Marie Remaut ${ }^{1}$, John Van Camp ${ }^{1}$, Stefanie Vandevijvere ${ }^{1}$, Margareta Vansant ${ }^{1}$
\end{abstract}

\section{Background}

Nutrition is increasingly recognised as a key determinant of public health. In 2003, the World Health Organization and Food and Agricultural Organization published a report (1) which includes a summary of current scientific knowledge concerning the relationships between nutritional factors and the most common diet-related diseases worldwide, such as cardiovascular diseases, cancer, obesity, type 2 diabetes, dental disorders and osteoporosis. Despite the overwhelming evidence pinpointing nutrition as a key determinant of public health, no coordinated national scientific organisation in the field of human nutrition existed in Belgium until last December. Although the reasons for this historical structural deficiency in Belgium are complex and multifactorial, three main causal mechanisms can be identified.

Firstly, the field of nutrition in Belgium is generally scattered. Nutrition research units are embedded in a variety of academic departments and often suffer from poor visibility. At the same time, nutritional education is integrated in different parts of programmes/curricula in universities and academic institutions and at a variety of levels. Although significant progress has been made during the last years and several nutrition courses are taught, a formal degree in human nutrition or public health nutrition does not exist. Neither is 'nutritionist' a recognised profession. Medical doctors only receive a few hours of training in nutrition and, at some universities they do not even acquire a basis in human nutrition at all.

Secondly, over the last decades, nutrition has been practically absent from the Belgian political agenda. It was only on the eve of the current millennium that things started to take a substantial turn as far as nutritional policy making is concerned. In 2004 the first nationwide food consumption survey was launched (2) and shortly after that, in 2006 , a national plan on

1 BNS founding members, Brussels, Belgium

Correspondence: info@belgiannutritionsociety.be 
nutrition and health was prepared and formally adopted by the Government (3). Despite these efforts, Belgium is still lagging behind as compared to many other European countries (4).

The most important priorities of this national plan are to inform the general public about a healthy diet and lifestyle, to develop tools for creating an environment which improves the dietary and physical behaviour of the population, to engage the private sector in tackling certain nutritional issues, to address the problem of micronutrient deficiencies, to monitor food and nutrient intake in the population and to stimulate nutrition research. Currently, representative data on nutritional habits and food intake in the Belgian population are scarce. Belgium still does not have a stable system of regular dietary monitoring, while this is common practice in various other European countries (5).

Finally, nutrition is intrinsically a multi- and interdisciplinary scientific activity with a typical complex causality. The determinants of nutritional problems are often found in seemingly unrelated areas (e.g. the role of urban planners or agricultural economics in the fight against the epidemic of obesity). Consequently, solutions to nutritional problems of today will require mobilisation of different disciplines. Such interdisciplinary collaboration is not easily achieved and requires leadership and long lasting partnerships with various stakeholders.

\section{Foundation of the Belgian Nutrition Society}

The issues identified above are clearly intertwined and require structural solutions. National fora are needed to bring together scientists active in the field of nutrition. For this - and other purposes - a structure was created that offers a forum for an interdisciplinary group of scientists in the broad field of human nutrition and related domains (physiology, biochemistry, epidemiology, food technology, dietetics, psychology, social sciences, behavioural sciences, animal feeding, ethical and legal issues, etc.).

From September 2007 onwards, a small group of scientists active in the field of nutrition, including members of various key scientific institutions in Belgium, met regularly to prepare a blueprint of the structure and statutes of a nutrition society and to determine its main objectives.

The Belgian Nutrition Society (BNS) was born out of this effort. The BNS aims to be an interdisciplinary network of active scientists in the field of human nutrition. Its main objectives are to stimulate scientific research in the field of human nutrition, to foster collaboration between Belgian scientists working in this area, to disseminate scientific knowledge with regard to human nutrition for the enhancement of public health, to be a reference point for information concerning human nutrition, and to advocate for research in human nutrition and for the implementation of policies and practices related to public health nutrition.

The BNS welcomes scientists from a wide range of areas and disciplines, spanning everything from fundamental research to social and behavioural sciences, but with a common interest in human nutrition. These various disciplines will work together to improve public 
health. Affiliated membership is open to others interested in this broad field. Membership of BNS can be obtained by submitting an application form and a declaration of interest.

The launching ceremony of the BNS took place on the 18th of December 2008 in the Royal Academy Palace in Brussels. The programme featured representatives from international umbrella organisations with regard to nutrition sciences such as the European Federation of Nutrition Sciences. The BNS Executive Board was introduced and the objectives and scope of the organisation were presented to the audience.

\section{More information}

More detailed information can be found on the BNS website at http://www.belgiannutritionsociety.be. For more information related to membership, contact the secretariat at info@belgiannutritionsociety.be.

\section{The BNS founding members}

Patrice Cani, Peter Clarys, Antoine Clinquart, Stefaan De Henauw, Nathalie Delzenne, Peter Deriemaeker, Caroline Douny, Isabelle Guelinckx, Inge Huybrechts, Lieven Huybregts, Patrick Kolsteren, Carl Lachat, Isabelle Laquiere, Yvan Larondelle, Jef Leroy, Guy Manghuin-Rogister, Christophe Matthys, Patrick Mullie, Jean Neve, Marie-Louise Scippo, Isabelle Sioen, Anne-Marie Remaut, John Van Camp, Stefanie Vandevijvere, Margareta Vansant

\section{References}

1. Diet, nutrition and the prevention of chronic diseases. Report of a joint WHO/FAO consultation. Technical Report Series 916. 2003. Geneva, World Health Organisation (WHO).

2. De Vriese S, Debacker G, de Henauw S, Huybrechts I, Kornitzer M, Leveque A et al. The Belgian food consumption survey: aims, design and methods. Arch Public Health 2005; 63:1-16.

3. Federaal Ministerie van Sociale Zaken VeL. Nationaal Voedings- en Gezondheidsplan 2005-2010. 2005.

4. Lachat C, Van Camp J, de Henauw S, Matthys C, Larondelle Y, Remaut-De Winter AM et al. A concise overview of national nutrition action plans in the European Union Member States. Public Health Nutr 2005; 8(3): 266-74.

5. Ocke M, Hulshof J, Bakker MI, Stafleu A, Streppel MT. Naar een nieuw Nederlands voedingspeilingsysteem. 350050001/2005. 2005. Nederland, RIVM. 